\title{
A A
} ARMADILHA
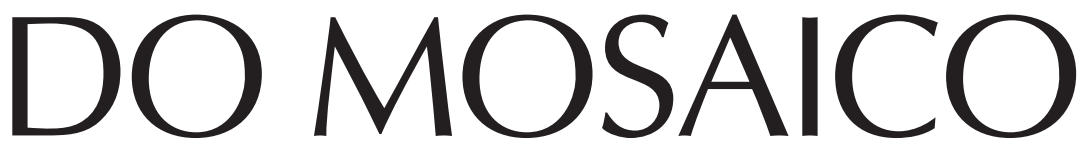

$\mathrm{P}$ ensar o fato surpreendente é uma das formas de questionar a realidade, ainda que a surpresa advenha, no geral, menos da natureza do evento que impacta, e bem mais da dificuldade de integrá-lo numa construção lógica da realidade que é condição para, cada qual, poder pensar o seu estar no mundo e na História. O inusitado subverte o tranqüilo domínio de nossas circunstâncias, sugere pertencimentos insuspeitados, vinculações não percebidas. $\mathrm{O}$ inesperado funciona como sinal de alerta ao apontar para os limites da natureza autocentrada da visão de mundo que sustenta as nossas certezas (ou baliza as nossas inquietações). E o surpreendente incomoda ao revelar, ainda que de relance, a extraordinária operacionalidade do conceito de totalidade (universo da perquirição, da História), por oposição à sua versão banalizada de globalização (universo da certeza, do dia-adia), tão em voga hoje em dia.

Essa preliminar é imposição da leitura do livro de Aleksandar Jovanovic, dos problemas que sugere e coloca. $\mathrm{O}$ autor trata de aspectos multifacetados de um espaço sociocultural que tem sido pródigo em produzir eventos (para o bem e para o mal) que surpreendem aquela parcela da humanidade que tem acesso às informações divulgadas pela mídia, e se interessa por elas. Afinal, é da feição desse quadrante da Europa - a CentroOriental-que as surpreendentes irrupções que aí tenham lugar são erigidas em paradigmas cristalizando marcos de periodização (e de ruptura), escapando ao observador menos atento as enormes ambigüidades das quais são portadores. Isso é consequiência tanto do papel que, por fetichizados, lhes cabe de simplificadores
ISTVÁN JANCSÓ

é professor do

Departamento de

História da

FFLCH-USP.

À Sombra do Quarto Crescente (Notas sobre a História e Cultura da Europa CentroOriental), de Aleksandar Jovanovic, São

Paulo, Hucitec, 1995.

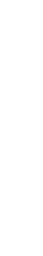
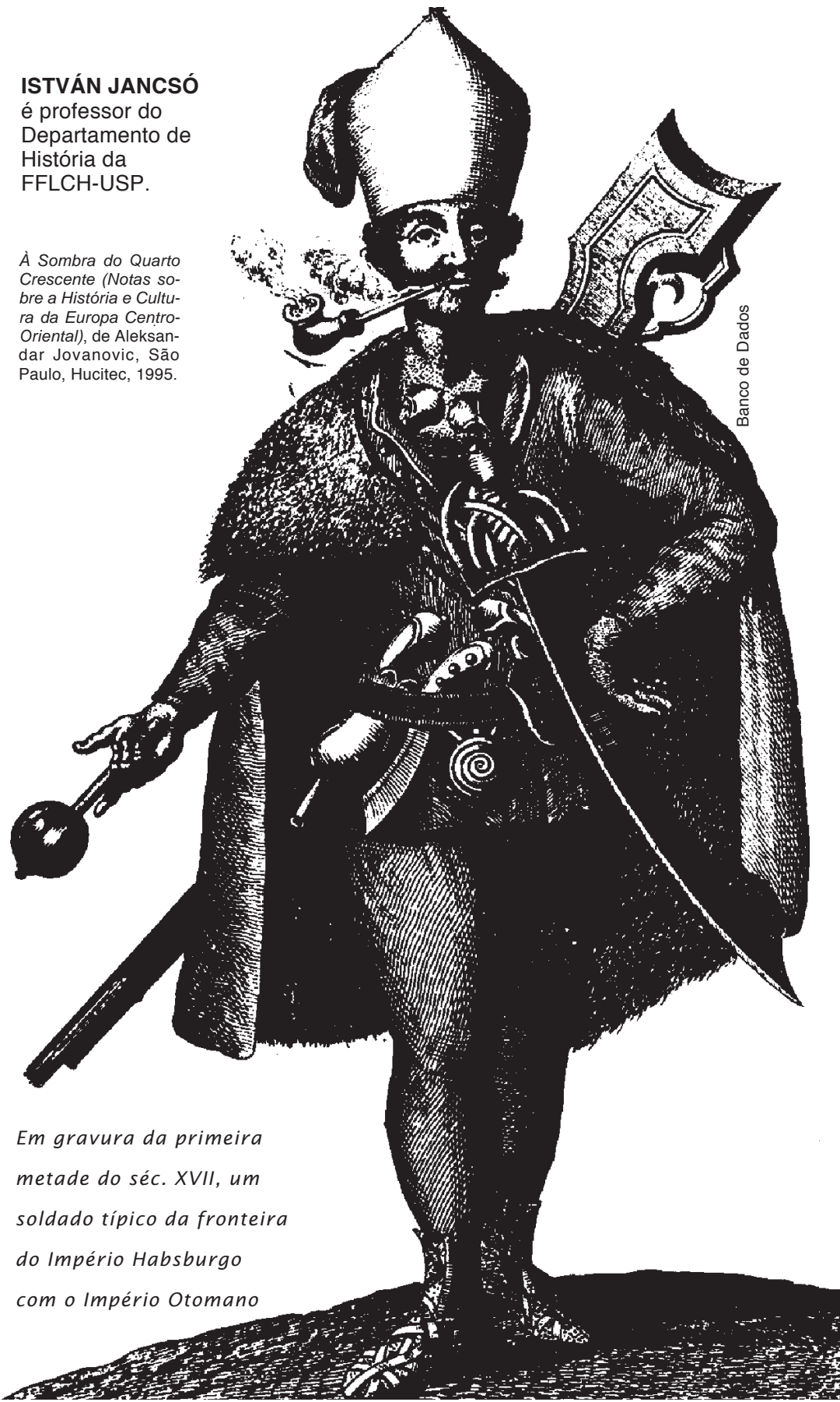
dos processos que estavam na sua base, e em cujo interior reside a complexidade que contêm as chaves do seu verdadeiro mistério, quanto da generalizada urgência na recomposição das circunstâncias familiares com base em códigos aconchegantes.

É por isso que a Queda do Muro de Berlim aparece mais consistente que qualquer muro, na condição de marco do colapso da bipolaridade até então vigente, e tende a esmaecer na memória coletiva o fato de que o muro-barreira física já estava literalmente obsoletizado quando da sua derrubada, mesmo antes da abertura das fronteiras da Polônia e da Hungria. E poucos se dão conta de que a lembrança da progressiva obsoletização do muro (e de tudo que significava) é, entretanto, cuidadosamente preservada pelos naturais destes Estados, como bem atestam os fragmentos de arame farpado dotados de certificado de origem numerado, selado e garantido pelo Setor de Material Bélico do Exército Popular da Hungria (a data é de 1989), como expressão da "vontade do povo húngaro" na remoção da "cortina de ferro que simbolizava, fisicamente, a divisão do continente europeu" (1). Ora, bastaria ter lido, à época, "Descaminhos Húngaros" (1985) e "Acasos Poloneses" (1986), de Enzensberger (2) para escapar do fascínio da simplificação. A releitura desses ensaios de um viajante interessado no curso das coisas ajuda, ainda que não se conheçam muitos detalhes das histórias específicas, nacionais, destes povos, no reconhecimento de que o deslocamento de significados centrados no muro somente se pode dar em paralelo com a permanência das muitas leituras particulares, com o que todo o processo subjacente torna-se, senão menos surpreendente, ao menos mais inteligível.

Porque, na verdade, não há mistério algum ou, ao menos, não existe, nesta parte da Europa de que trata Jovanovic, algo de essencial que dela faça uma entidade irredutível ao conhecimento numa escala superior à que vale para qualquer outra parcela do gênero humano. Existem aí, isto sim, trajetórias particulares, cuja percepção partilhada está na base dessa alquimia cuja resultante é a nação, e cujo arcabouço institucional é o Estado nacional (ou, na falta dele, de seu projeto). Tra- jetórias nacionais, Estados nacionais (ou projetos de), estamos diante de realidades históricas e de categorias mentais mediante as quais os corpos sociais que através delas percebemse a si mesmos apenas podem completar esse movimento quando são capazes de precisar os que lhes são estranhos na sua condição de portadores de atributos diferentes. A identidade somente se realiza em si mesma quando é capaz de pensar-se como alteridade. Daí a importância do notável insight de Benedict Anderson (3), ao formular a idéia de que as nações se constituem através da consciência compartilhada da reiteração de suas peregrinações, vale dizer, de peregrinações entre outras peregrinações, cada qual se reiterando no seu próprio percurso e, ao mesmo tempo, reconhecendo-se no espelho das outras que a refleteme, refletindo, dão forma à sua imagem.

Eis aí uma questão central que perpassa o livro de Jovanovic: a da diversidade. É de ressaltar o trato gentil dessa dimensão angular das relações entre os homens numa região do mundo que tem sido tudo, menos civilizada no enfrentamento desta questão. A ênfase está nas especificidades, todas elas legítimas e respeitáveis, de cuja justaposição resulta um mosaico cuja chave está na demarcação da polaridade básica que organiza o discurso: civilização contra barbárie, a cruz contra o quarto crescente. É dessa polaridade radical que resulta o esboço de um destino comum, em cujo interior as diversidades assumem a feição de acidentes históricos a gerarem sua lógica, eventualmente perversa. Estamos, portanto, face a identidades sugeridas, cuja alteridade é uma sombra, e é esta sombra que reflete a identidade comum insinuada no seu reflexo. Enfim, nada de História, apenas situações históricas pontuais, quase ilustrações. Nada semelhante ao sonho românticosubversivo de um Konrád, a respeito de uma Europa Central solidária, ancorada numa percepção da História que está acima dos contingentes fenômenos de massa (4).

É claro que tudo isso em termos, pois a ninguém é dado pular a sua própria sombra. A estratégia da exposição desautoriza a simplificação da assertiva, já que o autor opta pelo modelo do mosaico, pelo que abre mão da perspectiva. Mas tal qual os mosaicos 
bizantinos, que eram sobremaneira hieráticos, e nisso residia a lógica de seu discurso, a obra de Jovanovic é dotada de estrita organicidade. Não é por acaso que o autor rompe com a cronologia: otempo desmancha-se na sombra que esfuma as diferenças. Daí que os ensaios sobre temas literários começam pelo século XIX ("Hungria, 1848: a Literatura no Palco da História") retroagindo, a seguir, quase trezentos anos ("Poesia e Prosa na Hungria do Século XVI"), remontando mais ainda (1389) para, via A Batalha de Kossovo na Literatura da Sérvia, retornar ao século XX (5).

Este pequeno ensaio (pp. 176-91) erigese como o núcleo forte do livro, organizando as referências a esse evento demiúrgico, dispersas pelas diversas partes da obra, num conjunto significante. A primeira grande batalha do Campo dos Melros, em 1389, resultou na derrota de um exército cristão comandado pelo rei Lazar Khrebeliánovitch, diante das forças do Império Otomano do sultão Murad, o primeiro desse nome (6). Na esteira da derrota, o nascente Império da Sérvia perdeu sua autonomia, subsistindo entretanto como entidade política subordinada às potências em confronto, na dependência dos azares do conflito aí já então instaurado em caráter de permanência. Os desdobramentos futuros desse fato político têm várias versões, pelo menos tantas quantas são as histórias nacionais que julgam pertinente considerá-los na busca do entendimento das suas peregrinações particulares. O nosso autor destaca dois pontos: o primeiro diz respeito a uma memória; o segundo diz respeito a uma trajetória.

Quanto à memória, rastreia com pertinência a construção coletiva de uma "ética do dever, colocada acima da dicotomia entre a vida e a morte", fundamento da identidade nacional sérvia. Localiza a raiz dessa ética na tradição popular, aceita como fundadora de sua própria legitimidade. Esta via, "cristalizada na épica oral, legou um poema - 'O Juramento do Príncipe' - que sintetiza essa ética do dever nas palavras atribuídas ao rei Lazar: 'Quem não vier lutar em Kóssovo,/ De suas mãos nada brotará de novo, / Nenhum ramo de trigo na campina,/ E na encosta, nenhum fruto na vinha'. Ao longo de seis séculos, esta visão do dever de lutar pela sobrevi- vência da nacionalidade, sob quaisquer circunstâncias, tem ecoado como uma espécie de juramento iniciático do povo sérvio" (7). Guardemos estas palavras.

Quanto à trajetória da nação, Jovanovic assinala que a batalha do Campo dos Melros "deixou dois selos trágicos subseqüentes na História da Sérvia: primeiro, em 1389, o desaparecimento do reino e o início do processo de dominação otomana sobre as terras habitadas por esse povo; depois, no final do século XVII, a grande diáspora que resultaria na fuga massiva dos sérvios rumo ao norte da Península Balcânica e até mesmo rumo às planícies húngara e ucraniana" (8). Peregrinação entre peregrinações, a da nação sérvia revelase no texto sem contraface, sem espelho, sem atrito com outras peregrinações, identidade em marcha sem alteridade. Por quê?

Convém lembrar que o reino não desapareceu, e o autor lembra que o filho de Lazar, Stefan Lazárevitch, sobe ao poder preservando a dinastia, consolidando uma referência de legitimidade que será argüida, três séculos depois, por um Brankovitch tardio, junto à Corte de Viena, no percurso que o leva, finalmente, a se proclamar déspota da Ilíria (9). A alteração que advém, na esteira de 1389 , se dá no rearranjo da posição deste Estado no complexo sistema de hegemonias e subordinações, suseranias e vassalagens, que era a regra geral da organização política européia deste período de dissolução do sistema de Estados da Europa medieval, do qual o Império Otomano é partícipe, ainda que com marcada especificidade. Ora, Jovanovic sabe disso, o que impõe que se ressalte no texto a sua peculiar articulação de duas das dimensões do processo histórico: mudança e permanência. A idéia de permanência situa-se na nação, e esta se preserva na memória e na diáspora. Nesse sentido, os deslocamentos de populações sérvias aparecem sob o signo da sobrevivência, eé nele que se legitimam. Mas se no plano da nação a permanência se articula com a idéia da mudança (os deslocamentos), no plano do Estado esta articulação é rejeitada, e Kossovo Pólie passa a ser o marco de uma ruptura, de um ponto terminal da memória que, resgatado nessa condição pela reiterada peregrinação da nação, torna-se
5 Uma primeira versão deste ensaio, porém com estrutura e objetivos diversos, tura e objetivos diversos, centrado no conflito étnico servio-albanês, foi dado à
luz por Jovanovic como parte de "Yugoslávia - uma constelação cultural", in Revista USP no6, São Paulo, jun.-ago./1990.

6 Uma segunda batalha teve lugar no mesmo local, entre exércitos otomanos e cristãos, em 1448, com outra vitória otomana. A esse respeito ver, entre outros:F. Szakály, Virágkorés tros:F. Szakály, Virágkorés Hanyatlás, Budapest, Háttér Lap-és Könyvkiadó,
1990, pp. 41 e seg.

7 A. Jovanovic, À Sombra do Quarto Crescente, São Paulo, Hucitec, 1995, p. 179.

8 Idem, ibidem, p.178.

9 Idem, p. 246. Este personagem é sobrinho de um bispo da igreja ortodoxa da Transilvânia Acaba sendo prensivan 168 . Acaba sendo preso em 1689 e como tal reme. Szekfü in B. Hóman e Gy Szekfü, Magyar Történet, Budapest, K.M.Egyetemi Nyomda, 1935, v. 4, p. 259. 
constitutivo da própria identidade nacional.

Para que se possa avançar no desvendamento dos significados atuais dessa articulação de movimento (diáspora) e memória (a batalha de Kossovo Pólie), as comemorações do seu sexto centenário (1989) oferecem um campo fecundo.

Os preparativos implicaram numa mobilização extraordinária de recursos na Iugoslávia de então. Governo, universidades, academias de artes e ciências, o sistema escolar de todos os níveis, televisão, escritores, durante mais de um ano centraram seus esforços nos festejos, que atingiram seu ápice na grande missa de 28 de junho. A Igreja, que durante longo período foi mantida à margem e desacreditada pelo regime comunista, retorna espetacularmente e se coloca no centro das celebrações. "A festa foi um triunfo. De todos os quadrantes do país, da Europa e das Américas, passando pela Austrália, os sérvios afluem para Kossovo para aí saborearem sua révanche, e selarem os reencontros sobre a tumba do soberano Lazar" (10) ou, nas palavras do nosso autor, reiterarem o seu juramento iniciático. Mas espraiou-se uma sombra sobre os festejos. A população albanesa de Kossovo usou da sua recusa em participar das comemorações para contrapor à memória de uma peregrinação magnificentemente reiterada (a da nação sérvia) a irrecusável concomitância de uma outra, tão real e carregada de memória e de atualidade quanto aquela festejada: a sua própria. Pois é dessa outra peregrinação, com sua própria memória, marcos, heróis, fetiches e demais consequiências muito palpáveis que resultou o fato demográfico (este inquestionável) de que $80 \%$ da população de Kossovo é etnicamente albanesa, com as implicações culturais, políticas, religiosas ou econômicas desse fato matricial (todas estas questionáveis e questionadas).

Tal é a armadilha do mosaico: ele sugere mais do que mostra. Na Europa centro-oriental, cujo contorno é esboçado na obra, cabem, entre outros, a Hungria e a Macedônia, mas falta lugar, entre outros, para a Albânia. Não se trata de apontar ausências ou lacunas, já que a escolha das peças do mosaico cabe apenas ao seu autor. Mas não pode deixar de surpreender que situações particulares de natureza biográfica, tidas por típicas de um período (ainda que portadoras de características únicas, como a preservação na memória coletiva mediante a poesia, a atraírem a atenção do autor), não sejam confrontadas com outras que permitam configurar suas condições de expressões particulares de tendências gerais ou, em caso contrário, de situações excepcionais contrapostas ao curso geral, ainda que contraditório, do processo em pauta.

Essas ponderações são motivadas pelas ênfases do ensaio "Mehemet Sócolovitch, um Sérvio no Comando do Império Otomano" (pp. 250-9). O personagem é fascinante, não apenas por sua trajetória pessoal, mas porque esta insere-se na lógica da expansão e consolidação tanto daquele Império, quanto dos mecanismos de ordenamento das diversidades étnicas, políticas ou religiosas que estavam na sua base. Mas esta operação implica em tentar penetrar na racionalidade do próprio Império Otomano, e não apenas registrá-la com base na sua sombra.

Nunca é demais lembrar que o Império Otomano era portador de um aparente paradoxo mal esclarecido, e cujo trato é angular para que se possa compreendê-lo. Afinal, "como é que uma política definida como muçulmana pôde viver assente no conceito sistematizado de muçulmanos escravos?" (11). A superação do paradoxo passa pelo reconhecimento da instauração, desde os primórdios de sua constituição, do princípio de que "o Estado é propriedade do sultão, e ao mesmo tempo de todos os súditos diretamente ligados à sua pessoa" (12). Sustentado por um poderoso exército, cujo aríete era formado pelos infantes janízaros, tropa de elite profissionalizada, inteiramente dedicada às tarefas militares a ponto de impor o celibato aos seus membros, e pelos sipahis, estes constituindo uma cavalaria cuja base material residia na posse temporária de unidades produtivas cujo usufruto não-hereditário dependia do desempenho militar, o Império Otomano desenvolveu uma estrutura organizacional e administrativa também profissionalizada e altamente eficaz, cuja tarefa consistia, acima de tudo, em assegurar o 


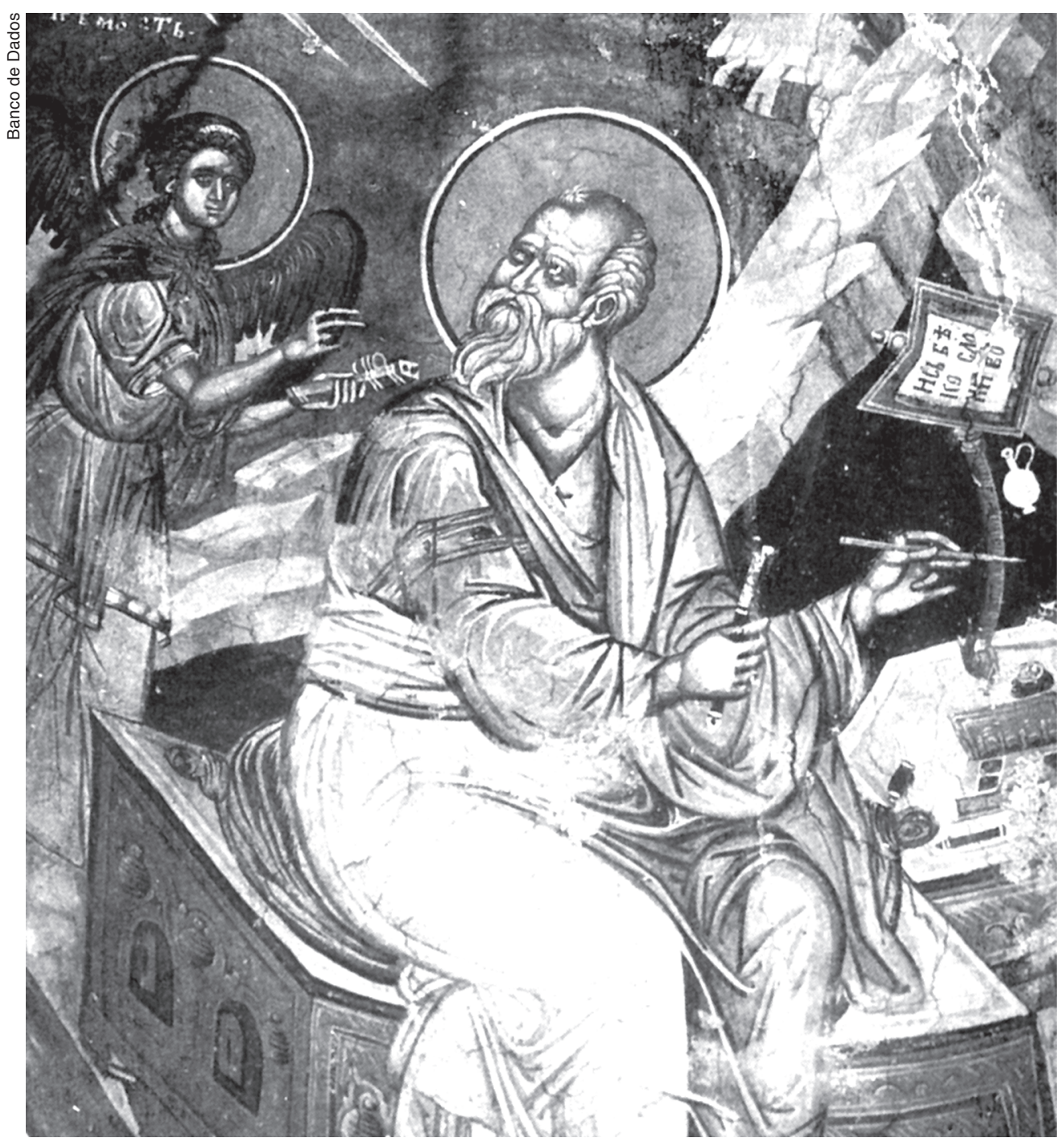

Detalhe de afresco da Igreja da Virgem, em Pêtch, Sérvia, representando o apóstolo João necessário fluxo dos impostos para fazer face às exigências da política da Sublime Porta. Como a saúde do Império dependia desse fluxo de recursos, dentre os quais um era o tributo de sangue implicando na entrega compulsória de crianças a serem educadas para a reposição das tropas de janízaros, ou destinadas a outras funções da administração civil, e como a escala do excedente - inclusive humano - passível de tributação dependia da capacidade de garantir condições gerais adequadas de reiteração da vida social, percebese que o objetivo maior do comando do Império era o de assegurar a ordem interna e, em paralelo, as condições de conquista (13). Como o grosso da tributação incidia sobre as populações não-islamizadas, não é difícil perceber que, por um lado, a adesão ao Islão tinha atrativos que não eram de pouca monta e, por outro, a razão pela qual o Império nunca se empenhou num esforço massivo de islamização das populações submetidas. O que caracterizou as relações deste com os Estados conquistados foi uma estratégia de controle lenta e gradual, principiando pela imposição do reconhecimento da suserania acompanhada do pagamento de tributos, mas com a preservação das estruturas sociais e de poder anteriormente vigentes. Como esta fase implicasse em conflitos, e a vassalagem era reafirmada por força das armas, as incursões militares em que isso implicava resultavam na progressiva exaustão das condições operacionais dos Estados vassalos semi-autônomos, cujas condições de resistência eram lenta e metodicamente trituradas. É esta a
13 Não se deve esquecer que, desde sua irrupção no continente europeu, o primeiro tratado firmado entre Istambul e qualquer Estado cristão qualquer ão que implicava no reconhecimento de perda territorial por parte da Sublime Porta foi o de Carlovitz (1699). 
14 Cf. K. Péter, A Magyar Romlásnak Századában, Budapest, Gondolat, 1975 e Zs. Újváry, "Nagy két császár birodalmi között", Budapest, Gondolat, 1984.

15 Cf. L. Makkai e Z. Szász (org.), Erdély Története,
Budapest, Akadémiai Kiadó, 1986, v. II, pp. 720 e seg.

16 É esta dificuldade que leva Eric Hobsbawn a contornar o problema através do recurso à formula do pro curso à formula do proNacionalismo desde 1780 (Rio de Janeiro, Paz e Terra, 1990).

17 A. Jovanovic, op.cit., pp. 244 e seg

18 Essa informação é significativa para que se possa acompanhar o nexo da construção das identidades-alteridades noperído. o resto, tanto ó que Jovanovic aponta para fato em outro estudo, ind cado na nota 5 (p. 51). De resto, cabe lembrar que Péter Zrinyi termina seus dias executado por envolvimento na primeir das muitas consimeira das muitas conspiraçoes anti-Habsburgo da nobrez húngara, episódio que ficou registrado na História como a conspiração de Wesselényi. Cf. B. Hóman e Gy Szekfü, op.cit., v. 4, pp. 171 e seg.

19 Adendo a um dos manuscritos revisados de Adriai tengernek Syrenaia, apud S. I. Kovács: Utószó as Adriai Tengernek Syrenaia hasonmásos kiadásához, Budapest, Akadémiaikiadó Magyar Helikon, 1980, p. 9. Jovanovic não deixa de referir essa circunstância em op. cit., p. 175, nota 5 , destacando o fato de que "Péter (ou Petar) era nacionalista croata". natureza geral do processo que levava à dissolução das estruturas políticas e sociais tradicionais e propiciava a incorporação destes espaços socioculturais diferenciados ao sistema administrativo imperial diretamente centrado em Istambul (14). Como o ritmo desse processo variava de caso para caso, mas em cada uma das situações a islamização não era consistentemente estimulada, percebe-se que, na falta de uma aristocracia hereditária dotada de base material própria (metodicamente triturada, conforme já foi dito), a emergência de elementos de variada origem étnica em posições de mando dependia em grande parte de um misto de qualificação funcional e senso de oportunidade, cuja única precondição era a conversão à fé do Profeta. Dessa forma, a trajetória de Sócolovitch é variante de uma possibilidade de ascensão social em aberto e mais ou menos generalizada, cujo ponto culminante, em termos de escala de poder e de importância histórica, está no grão-vizir Mehmed Köprölü, etnicamente albanês, na segunda metade do século XVII (15).

Esta lembrança é útil apenas para ilustrar os tortuosos caminhos da construção da memória, processo acima de tudo seletivo e comprometido com o presente. Daí vem que os fragmentos de passado apenas podem adquirir sentido se pensados na sua estrita historicidade, o que, no tocante à obra de Jovanovic, remete a algumas questões. A primeira diz respeito ao risco da teleologia. A segunda implica em considerar a diversidade dos ritmos históricos no interior de um mesmo processo geral.

Quanto à primeira questão, convém não esquecer que as nossas categorias que expressam identidades nacionais são pouco indicadas para compreender identidades nacionais passadas, não porque no passado estas inexistissem, mas porque a diversidade das peregrinações então percebidas era construída com base em significados totalmente distintos dos nossos. A diversidade das peregrinações e de sua presença enquanto memória partilhada, fundamento das consciências nacionais, somente adquire sentido enquanto pernanência, se percebida sob o signo da mudança, da sua historicidade (16).
É por esse motivo que espanta o recurso a categorias contemporâneas na valoração mais ou menos taxionômica de personagens do passado. Ao se referir a Miklós Zrinyi e seu irmão Péter (17) (Petar Zrinski, no texto) - "Ofensiva Antiturca no Século VII", pp. 243-59 -, as identificações de tipo étnico como referenciais para o nacional, no período, aparecem deslocadas. Assim é que Miklós surge como nacionalista húngaro de origem croata, e Péter, pela grafia adotada de seu nome, como "governante da Croácia", cuja condição de parte integrante do reino húngaro não é referida (18). As identidades apontadas insinuam alteridades que uma análise histórica rejeita, e tornam impenetráveis fórmulas como a do próprio poeta ao falar de seu irmão: "Conheço de há muito o bravo filho de Marte, conheço-o, conheço-o ao tocar seu cavalo. Ele é meu irmão; como magiar, como croata, vê-se que muito ama a sua pátria" (19). Ainda que a tradução careça de engenho e arte, percebe-se que a pátria é uma (no caso o Reino de Hungria), e em seu interior ser magiar ou croata não é conflitivo. É por isso que não é contraditória a dedicatória que precede a apresentação da Sereia do Mar Adriático, de Zrinyi: “dedico este meu trabalho à nobreza magiar" (20), e nem o é o fato de antecipar ao leitor que "misturei [ao húngaro] palavras turcas, croatas e latinas nos meus versos, pois os julguei mais belos dessa forma" (21). Afinal de contas, a nação era tida pela nobreza, e os seus contornos definiam-se com base nas liberdades (direitos, privilégios) desta. Isso significa que poder-se-ia ser de origem étnica outra que não a húngara, mas ser membro da nobreza magiar. O atributo de língua não era impeditivo da participação na trajetória da nação assim configurada, e a alteridade expressa nesse atributo específico não configurava alteridade de natureza política, vale dizer, nacional (22). Quando Péter Zrinyi publica em Veneza a obra de seu irmão vertida para o croata, tem como intenção ampliar a divulgação de um texto de alto poder de mobilização antiturca (23), e não movido por um nacionalismo avant la lettre. Esse significado das relações interétnicas ressalta na obra de um prosa- 
dor húngaro do século XVI contemplado no ensaio "Poesia e Prosa na Hungria do Século XVI" (pp. 169-75), Péter Bornemisza (24).

Pregador de grande talento, erasmiano, humanista numa área periférica em relação aos centros irradiadores do humanismo europeu da época, como periférico era, entre outros, o humanismo ibérico (25), Bor nemisza tanto traduz Electra para o húngaro, ambientando a peça na Hungria de seu tempo (26), quanto define um programa de aperfeiçoamento literário da língua magiar através de uma obra volumosa. Isso que não o priva de interagir com pastores-pregadores protestantes de outras etnias e falantes de outras línguas (o eslovaco, o alemão), reconhecidos por ele como seus iguais, elementos constitutivos da nação húngara, vale dizer, de suas liberdades (desiguais) partilhadas ou, no dizer de János Balassi (em 1555), "de sua constituição" (27). A idéia de pátria repousa sobre a percepção da espacialidade da trama das liberdades (direitos, privilégios), às quais Bornemisza acrescenta enfaticamente a religiosa, que configuram as constituições nobiliárquicas cuja vigência é reiterada nas Cortes, Estados Gerais, Dietas ou, no caso da Hungria, em língua magiar - Országgyülés. É aí que a nação se materializa e se reitera, e quem dela participa (ou representa) é parte da nação. E a sombra que ameaça a nação assim concebida é aquela que implica em risco para a organicidade e a estabilidade do sistema legal ordenador das diversas liberdades desiguais que lhe configura o nexo.

A partir de agora torna-se mais fácil tratarmos do segundo ponto, ou seja, da necessidade de que seja considerada a diversidade dos ritmos históricos no interior de um mesmo processo geral. Como no nosso caso o elemento ordenador do curso geral é a "sombra do quarto crescente", o que se há de ponderar é que esta sombra, por um lado, adquire matizes bastante diversas a depender do grau de preservação das condições historicamente dadas de reiteração das nações. Isso implica em perceber que há uma grande diferença entre situações em que se constata a permanência das relações sociais normatizadas conforme o padrão ocidental (o que implica em entender as tensões e os conflitos daí derivados) e outras que resultaram no deslocamento do eixo da consciência de pertencimento a uma comunidade imaginada (ainda a nação) para outra esfera (a Igreja Ortodoxa, em vários casos). Não se trata de garimpar escalas de precedência do tipo "mais ou menos moderno", "superior ou inferior". Trata-se, em primeiro lugar, de perceber diferenças nas configurações nacionais e nas suas histórias, cada qual gerando novas permanências e esquivandose de novas sombras. Afinal, esta região não é apenas a da presença ou da ameaça otomanas (e de sua memória). Mais do que isso, é a charneira de três grandes impérios continentais: o Império Russo, o Império dos Habsburgos e o próprio Império Otomano. Se isso é eludido, as diversas identidades específicas (e das múltiplas combinações delas) tornam-se tão impenetráveis quanto o é a extrema diversidade constitutiva das identidades de outra charneira de grandes impérios, estes de vocação oceânica e mercantil: o Caribe.

$\mathrm{Na}$ introdução ao livro de Jovanovic, Nelson Ascher recorre a T. S. Eliot para lembrar que na Europa centro-oriental "nenhum conhecimento tem perdão" (28). Eu diria que ele tem razão, mas aduziria que a alternativa para a recusa do conhecimento é a barbárie, ainda que hoje em dia ninguém esteja autorizado a pretender que o conhecimento seja o seu antídoto. E Ascher também aponta para o caráter prismático da concepção do livro, "cujo tema central são as aporias e os conflitos da própria variedade cultural" (29), radicando nessa sua face o seu maior mérito. Talvez tenha razão. De minha parte penso que o mérito do livro reside principalmente no trato gentil das diferenças, na postura moral que rejeita o preconceito. Este é um privilégio dos lingüistas, que podem mostrar a concomitância das peregrinações através do estudo dos léxicos das línguas modernas. E é também gentil, talvez até em demasia, o recurso do autor em preservar a sua própria sombra, ainda que mediante o recurso ao mosaico, que mais sugere do que mostra. E, sobretudo, surpreende.
20 M. Conde Zrinyi, Adriai Tengernek Syrenaia, Viena, Kosmerovi Máte Ed., 1651 (ed. fac. sim.).

21 Idem, "Az olvasonak" ("Ao Leitor").

22 A não ser quando movimentos sociais populares, incompatíveis com a ordem nobiliárquica, de consistente base étnica e cultural, na busca de sua institucionalização, buscassem nos elementos da memório ele memoria coletiva os paradigmas de forma-
lização de seu contorno político. É o caso do episódio de Iván Fekete que, à frente de um amplo movimento popular radicado nos sérvios no sul da Hungria, ao ver-se face a face com a reação da nobreza húngara, propõe aliança a Ferdinando de Habsburgo, o qual lhe oferece o reconhecimento do título de déspota dos sérvios, vendo nele um aliado no esforço continuado de integrar a Hungria nos seus domínios. As tropas do tzar Ivan são derrotadas em 1527 e o movimento finda com a sua morte (cf. B. Hóman e Gy Szekfü, op. cit., v. 3, p. 28).

23 Cf. S. I. Kovács, op. cit., p 9.

24 A. Jovanovic, op. cit., pp. 171 e seg.

25 Ver, por exemplo: R. Morse "La Teoria Política de Gobierno Colonial", in $\mathrm{H}$ Bonilla (org.), Los Conquistados - la Población Indí gena en las Américas. Bogota, Tercer Mundo Ed. 1992.

26 I. Nemeskürty, Bornemisza Péter Kisértései, Budapest, Szépirodalmi Könyvkiadó, 1984, pp. 10 e seg.

27 Idem, ibidem, p. 18. A palavra utilizadaé alkotmány.

28 N. Ascher, "Europa, pois é Europa", in A. Jovanovic op. cit., p. 10.

29 Idem, ibidem, p.16. 